\section{APROXIMACIONES INMUNOANALÍTICAS PARA EL CONTROL DE XENOBIÓTICOS Y BIOTOXINAS EN ALIMENTOS}

\author{
Josep V. Mercader \\ Instituto de Agroquímica y Tecnología de Alimentos (Valencia) \\ Consejo Superior de Investigaciones Científicas \\ ORCID iD: https://orcid.org/0000-0002-1838-2647 \\ jvmercader@iata.csic.es \\ Antonio Abad-Somovilla \\ Departamento de Química Orgánica \\ Universitat de València \\ ORCID ID: https://orcid.org/0000-0002-5599-3682 \\ antonio.abad@uv.es \\ Consuelo Agulló \\ Departamento de Química Orgánica \\ Universitat de València \\ ORCID ID: https://orcid.org/0000-0001-6056-5087 \\ consuelo.agullo@uv.es
}

Antonio Abad-Fuentes

Instituto de Agroquímica y Tecnología de Alimentos (Valencia)

Consejo Superior de Investigaciones Científicas ORCID iD: https://orcid.org/0000-0001-5672-1438

aabad@iata.csic.es

Cómo citar este artículo/Citation: Apellidos, C., Apellidos, I. y Apellidos, I. (2020). Aproximaciones inmunoanalíticas para el control de xenobióticos y biotoxinas en alimentos. Arbor, 196 (795): a542. https://doi.org/10.3989/arbor.2020.795n1006

Recibido: 26 febrero 2019. Aceptado: 29 octubre 2019.

RESUMEN: El control efectivo de la calidad y seguridad de los alimentos requiere de métodos analíticos que garanticen la determinación fiable de cualquier sustancia potencialmente perjudicial para el consumidor que pueda estar presente en el alimento antes de su distribución y comercialización. Una de las aproximaciones analíticas que contribuye a garantizar este objetivo engloba una serie de técnicas que tienen en común la utilización de anticuerpos como elementos esenciales para la detección del analito diana, y que en conjunto reciben el nombre de métodos inmunoquímicos. Este artículo pretender aportar una visión básica de los principios bioquímicos subyacentes a estas tecnologías y cuáles son sus ventajas y limitaciones en la determinación de contaminantes químicos, residuos y aditivos en matrices alimentarias. En la última parte se comentan algunas de nuestras iniciativas en este ámbito que han dado lugar a kits rápidos disponibles comercialmente tras haber transferido la tecnología correspondiente al sector industrial.

PALABRAS CLAVE: inmunoensayo; métodos rápidos; ELISA; tira inmunorreactiva; hapteno; anticuerpo; calidad y seguridad de alimentos; contaminante; residuo.

\section{IMMUNOANALYTICAL APPROACHES FOR THE CONTROL OF XENOBIOTICS AND BIOTOXINS IN FOOD}

Copyright: (C) 2020 CSIC. Este es un artículo de acceso abierto distribuido bajo los términos de la licencia de uso y distribución Creative Commons Reconocimiento 4.0 Internacional (CC BY 4.0).

ABSTRACT: Analytical methods are required to effectively ensure food quality and safety. A reliable determination of any harmful substance potentially present in a food product is mandatory before it reaches the consumer. One of the analytical approaches that nowadays contributes to attaining this goal includes a series of techniques that use antibodies as essential elements for the detection of the target analyte, which collectively are known as immunochemical methods. This article aims to provide a basic overview of the biochemical principles underlying these technologies and their benefits and limitations for the determination of chemical contaminants, residues and additives in food matrices. In the last section, some of our initiatives in this field that resulted in commercially available rapid kits following technology transfer to the industrial sector are discussed.

KEYWORDS: immunoassay; rapid methods; ELISA; immunostrip; hapten; antibody; food quality and safety; contaminant; residue. 
Los métodos inmunoquímicos engloban un conjunto de técnicas analíticas en las que la sustancia a detectar (analito) es identificada y cuantificada mediante su reconocimiento molecular por un anticuerpo capaz de unirse a ella con una elevada afinidad y especificidad. Debido a una serie de características, entre las que destacan su simplicidad, rapidez, sensibilidad y portabilidad, los métodos basados en la utilización de anticuerpos como receptores biomoleculares constituyen un conjunto de técnicas bien establecidas con aplicaciones en diversos campos, incluyendo la detección y cuantificación de diferentes tipos de contaminantes en alimentos. Los anticuerpos se pueden utilizar para detectar proteínas y microorganismos patógenos o alterantes, así como para analizar sustancias de bajo peso molecular, como es el caso de antibióticos, hormonas, micotoxinas y plaguicidas, analitos en los que nuestro grupo de investigación ha centrado su actividad científica en los últimos quince años. La gran versatilidad de las técnicas inmunoanalíticas para la detección de xenobióticos y biotoxinas se pone de manifiesto en la variedad de formatos de ensayo que pueden adoptar para cubrir diferentes necesidades analíticas, como (i) la cromatografía de inmunoafinidad, para la purificación y concentración de un analito en la muestra antes de su determinación mediante métodos instrumentales, fundamentalmente cromatográficos; (ii) los inmunoensayos de flujo lateral o tiras inmunorreactivas, cuando lo que se necesita es un análisis sencillo y semicuantitativo que pueda realizarse en cualquier entorno; (iii) los biosensores, cuando la automatización es una prioridad; (iv) los microarrays y los sistemas basados en detección mediante citometría de flujo, como el Luminex, en aquellos casos en los que existe la necesidad de determinar varios analitos simultáneamente; y (v) los inmunoensayos enzimáticos en placa o ELISA (Enzyme-Linked ImmunoSorbent Assay), sin duda el sistema más extendido por su capacidad para analizar de forma cuantitativa y asequible un elevado número de muestras en poco tiempo.

En comparación con los métodos cromatográficos, los cuales están justamente considerados como la metodología de referencia para el análisis de moléculas orgánicas en el ámbito de la seguridad alimentaria, las técnicas inmunoanalíticas presentan algunas ventajas, aunque también ciertos inconvenientes (véase figura 1). Si bien una discusión en profundidad de los pros y los contras de ambas metodologías puede dar mucho de sí, no cabe duda de que las discrepancias más significativas se centran en la capacidad multi- rresiduo y en la portabilidad. Las técnicas instrumentales separativas son capaces de determinar simultáneamente la presencia de varios compuestos en una muestra, y esta es una de sus grandes virtudes. Por el contrario, los métodos inmunoquímicos presentan una importante limitación en este aspecto, dada la extraordinaria especificidad inherente a la interacción antígeno-anticuerpo, por lo que comúnmente solo pueden determinar un analito, o unos pocos si están estructuralmente relacionados. Se podría afirmar que, mientras los métodos cromatográficos están especialmente dotados para analizar un elevado número de compuestos en un limitado número de muestras, las técnicas basadas en la utilización de anticuerpos son especialmente adecuadas para analizar un limitado número de sustancias en un elevado número de muestras. En cuanto a la portabilidad, los métodos cromatográficos emplean equipos sofisticados que deben ser operados por personal altamente cualificado y en entornos bien dotados técnicamente. Por el contrario, las técnicas inmunoanalíticas, y muy especialmente los ensayos tipo ELISA y las tiras inmunocromatográficas, requieren de un mínimo equipamiento para su realización, lo que las convierte en procedimientos idóneos para llevar a cabo análisis in situ y obtener así resultados prácticamente inmediatos allí donde se requieran.

Figura 1. Comparación cualitativa de las prestaciones analíticas de los métodos cromatográficos y de las técnicas inmunoanalíticas

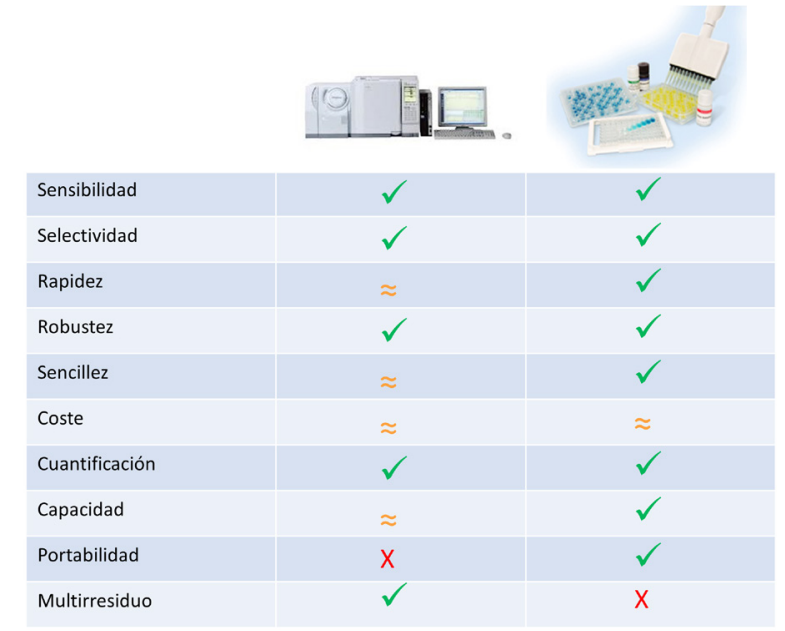

Fuente: elaboración propia

Como consecuencia de sus características y condicionantes, los métodos inmunoquímicos están especialmente indicados para una serie de aplicaciones, entre las que figuran: 
i) Crisis y alarmas alimentarias. La presencia en un alimento de un contaminante o residuo no permitido, o por encima de los niveles establecidos en la legislación, suele desencadenar un fortalecimiento temporal de los controles dirigidos hacia aquella combinación alimento-residuo responsable de la alarma. Ante situaciones de esta naturaleza, las técnicas inmunoanalíticas permiten realizar un cribado rápido de una gran cantidad de muestras en poco tiempo.

ii) Departamentos de control de calidad. Las empresas agroalimentarias, tanto de productos frescos como procesados, tienen frecuentemente la necesidad de realizar analíticas focalizadas en ciertas sustancias para garantizar que un determinado proceso se ha realizado correctamente y para evitar las cuantiosas pérdidas económicas y de imagen corporativa que la presencia de un contaminante particular podría acarrear, una situación en la que los métodos rápidos de cribado pueden resultar ventajosos en términos económicos y logísticos.

iii) Estudios de transferencia durante el procesado. Mientras que algunos compuestos químicos, debido a su estructura y propiedades, apenas son transferidos desde la materia prima al producto final (zumos, vinos, mermeladas, etc.), otros por el contrario no sufren merma alguna o incluso su concentración es superior en el producto procesado. Los métodos inmunoquímicos pueden con- tribuir a conocer mejor estos procesos y cómo afectan a la calidad sanitaria del alimento.

\section{LOS ANTICUERPOS COMO BIORRECEPTORES EN IN- MUNODETECCIÓN}

El componente fundamental de todo método inmunoanalítico es el anticuerpo, ya que sus propiedades de reconocimiento (afinidad y especificidad) condicionarán en gran medida las prestaciones analíticas del método desarrollado. Los anticuerpos son glicoproteínas producidas por el sistema inmunológico como respuesta a la exposición frente a un elemento extraño, como bacterias o virus. La estructura básica de los anticuerpos, también denominados inmunoglobulinas, está formada por dos cadenas polipeptídicas ligeras (L) idénticas de $25 \mathrm{kDa}$ y por 2 cadenas polipeptídicas pesadas (H) también idénticas de 50 kDa (Figura 2). Las cadenas pesadas se encuentran unidas entre sí por puentes disulfuro, y cada una de ellas está a su vez unida a una cadena ligera, también por puentes disulfuro. Tanto la cadena pesada como la ligera están organizadas en regiones variables y en regiones constantes. Cada molécula de anticuerpo tiene dos sitios de unión de antígeno, y cada sitio de unión está formado por la asociación de las regiones variables de una cadena pesada y una cadena ligera, localizadas en el extremo amino terminal. En función del tipo de cadena pesada, las inmunoglobulinas se clasifican en diferentes clases y subclases, siendo las del tipo IgG las más abundantes.

Figura 2. Estructura de una inmunoglobulina tipo IgG y de dos de los fragmentos más habituales: el fragmento Fab, obtenido por digestión enzimática del anticuerpo, y el fragmento scFv, obtenido mediante ingeniería genética

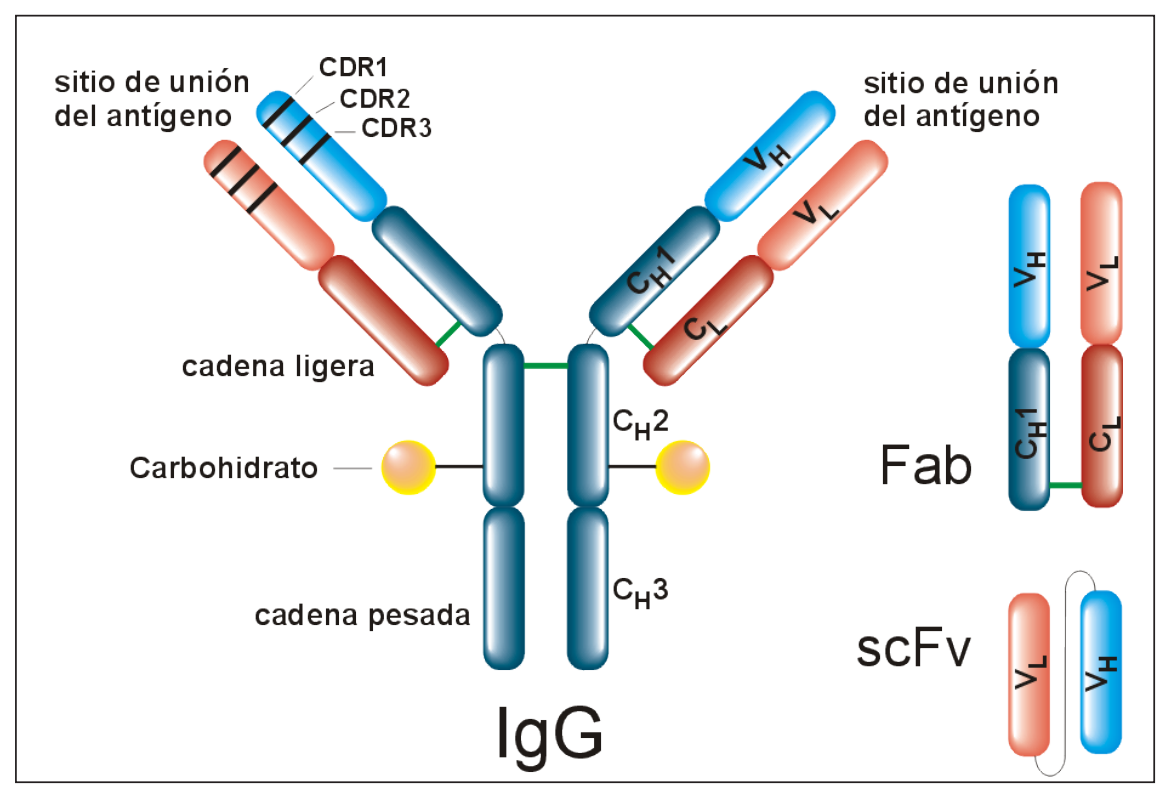

Fuente: elaboración propia 
En el contexto de la generación de anticuerpos con fines analíticos, biomédicos o biotecnológicos, estos pueden clasificarse en tres tipos según su origen: policlonales, monoclonales o recombinantes. Los anticuerpos policlonales se obtienen a partir del suero sanguíneo del animal inmunizado, y constituyen una mezcla compleja y heterogénea de todos los tipos de anticuerpos generados frente a un mismo inmunógeno, cada uno de ellos procedente de un clon de linfocitos $B$ distinto y por tanto con una afinidad y especificidad diferente. Por ello, sus características representan un promedio de la respuesta inmunitaria del animal, lo que puede ser útil para evaluar la idoneidad del inmunógeno empleado para la generación de los anticuerpos. Su obtención es relativamente sencilla, económica y rápida, pero presentan como principal inconveniente su carácter limitado y su escasa reproducibilidad debido a la variabilidad inherente al proceso de inmunización.

Los anticuerpos monoclonales son inmunoglobulinas obtenidas in vitro mediante la generación y cultivo de células especiales denominadas hibridomas, las cuales derivan de la fusión de un linfocito $B$ con una célula de mieloma. Dado que todo linfocito individual produce únicamente un tipo de inmunoglobulina, todas las moléculas de anticuerpo obtenidas a partir de una línea de hibridoma serán idénticas y tendrán las mismas propiedades de unión. En consecuencia, la tecnología de hibridomas garantiza una fuente ilimitada y reproducible de anticuerpos con unas características constantes. Su generación es más compleja y costosa, pero resultan más valiosos desde un punto de vista biotecnológico.

Finalmente, los anticuerpos recombinantes se obtienen mediante técnicas de biología molecular, ya sea partiendo de librerías génicas sintéticas o semisintéticas, o bien a partir de los genes codificantes de anticuerpos procedentes de líneas de hibridomas preestablecidas. La posterior clonación y expresión de estos genes en otros organismos da lugar a anticuerpos con propiedades bien definidas cuyo sitio de unión es susceptible de ser modificado por mutagénesis. Sin embargo, la utilización de anticuerpos recombinantes para la inmunodetección de sustancias de interés en alimentos es todavía testimonial desde un punto de vista comercial.

El sistema inmunitario está especialmente adaptado para generar anticuerpos frente a antígenos de elevado tamaño potencialmente patogénicos, tales como virus y bacterias, o proteínas exógenas. Sin embargo, los compuestos orgánicos de bajo peso molecular, como los fármacos, los plaguicidas o las micotoxinas, no son capaces de inducir por sí mismos la generación de anticuerpos, aunque sí pueden ser reconocidos por ellos; en otras palabras, no son sustancias inmunogénicas pero sí antigénicas. Karl Landsteiner, premio Nobel de Fisiología o Medicina en 1930 y considerado uno de los padres de la inmunoquímica moderna, bautizó a este tipo de sustancias con el nombre de haptenos (Landsteiner y Simms, 1923). Así pues, una de las dificultades para desarrollar métodos inmunoanalíticos para contaminantes y residuos químicos potencialmente presentes en alimentos radica en que su pequeño tamaño y su escasa complejidad estructural dificultan enormemente la generación de anticuerpos, biomolécula imprescindible para la detección. La clave para solventar esta aparente paradoja se encuentra en que los haptenos pueden convertirse en inmunogénicos si se enlazan covalentemente a una proteína para dar lugar a lo que se denomina conjugado proteínahapteno. De esta forma, el hapteno pasa a formar parte de los epítopos de dicha proteína, la cual sí es capaz de inducir la generación de anticuerpos tras un proceso de vacunación o inmunización.

No obstante, cabe señalar que en la mayoría de los casos en los que se desea generar anticuerpos frente a una molécula pequeña, no es posible su unión covalente directa a una proteína por carecer de algún grupo reactivo que pueda utilizarse para este fin. Resulta por tanto necesario sintetizar previamente un análogo del compuesto diana que lo mimetice con la mayor exactitud y que incorpore un grupo funcional que posibilite la conjugación. Desde el punto de vista inmunológico, dichos derivados sintéticos también son haptenos. A grandes rasgos, un hapteno funcionalizado está constituido por tres elementos básicos: una estructura principal semejante al analito de interés, un grupo funcional para la posterior unión covalente a la proteína, y un tercer elemento entre ambos denominado brazo espaciador. Cabe señalar que el derivado sintético debe poseer una estructura lo más parecida posible al analito, preservando sus principales elementos estructurales, su conformación y su distribución electrónica (Mercader, Agulló, Abad-Somovilla y Abad-Fuentes, 2011). De esta manera, los anticuerpos generados hacia el hapteno sintético reconocerán también al analito con una elevada afinidad y especificidad. El propósito del brazo espaciador es mejorar la exposición de la molécula al sistema inmunitario al separarla de la proteína transportadora, facilitando su interacción con los anticuerpos y otros receptores celulares y evitando el enmascaramiento parcial o total del hapteno por una proximidad excesiva a la proteína. Habitualmente, el espaciador consiste en una cadena 
lineal hidrocarbonada totalmente saturada con el grupo funcional en su extremo, como por ejemplo un grupo carboxilo, el cual posibilita el acoplamiento a la proteína a través de su reacción con los grupos amino libres de los aminoácidos básicos, principalmente lisinas, mediante la formación de un enlace amida. Es importante que el brazo espaciador no contenga elementos fuertemente inmunogénicos, como son anillos aromáticos, dobles enlaces conjugados o heteroátomos, ni que sea excesivamente polar, lo que podría cambiar la distribución electrónica de la molécula y desviar la respuesta inmunitaria hacia elementos no deseados que no están presentes en la estructura del analito (Vallejo, Bogus y Mumma, 1982). En cuanto a su longitud, se ha demostrado experimentalmente que una cadena de 4-6 átomos de carbono resulta generalmente adecuada para favorecer la exposición del hapteno al sistema inmunitario, lo que desemboca en la producción de anticuerpos con la deseada afinidad y especificidad hacia el compuesto diana.

Así pues, si bien en todo método inmunoanalítico el anticuerpo constituye un reactivo clave, en el caso de que la sustancia a detectar sea un compuesto de bajo peso molecular, la síntesis de haptenos se considera una etapa crítica por sus enormes implicaciones sobre la afinidad y especificidad de los anticuerpos generados. Es más, la introducción del grupo funcional en la posición deseada con frecuencia solo es posible mediante estrategias de síntesis total que conllevan un esfuerzo experimental considerable y una sólida formación en química orgánica sintética (Sanvicens, Pichon, Hennion y Marco, 2003). Incluso disponiendo de experiencia en esta temática, y pese a los avances que se han producido en los últimos años en técnicas de modelado molecular que posibilitan un diseño más racional de las estructuras más adecuadas con vistas a generar anticuerpos con las características deseadas, sigue siendo difícil predecir cuál de entre todas las alternativas viables será la más idónea. En consecuencia, una práctica habitual en nuestro grupo y entre algunos de los grupos de investigación más activos en esta área, consiste en sintetizar diferentes derivados del analito en los que el grupo funcional se introduce en posiciones alternativas del esqueleto de la molécula, maximizando así las probabilidades de éxito al presentar la molécula al sistema inmune mediante aproximaciones complementarias (véase figura 3) (López-Puertollano, Mercader, Agulló, Abad-Somovilla y Abad-Fuentes, 2018; Parra, Mercader, Agulló, Abad-Somovilla y AbadFuentes, 2012; Suárez-Pantaleón, Mercader, Agulló, Abad-Somovilla y Abad-Fuentes, 2011).

Las proteínas que con mayor frecuencia se utilizan para la conjugación covalente de haptenos son las albúminas y las hemocianinas, siendo la seroalbúmina bovina (BSA) una de las más empleadas en la preparación de conjugados de inmunización por su elevada tolerancia a cargas hapténicas altas sin pérdida de solu-

Figura 3. Estructura del fungicida pyrimethanil y de diferentes haptenos sintetizados con vistas a la generación de anticuerpos. El brazo espaciador y el grupo funcional, situados en posiciones alternativas de la molécula, se muestran en rojo

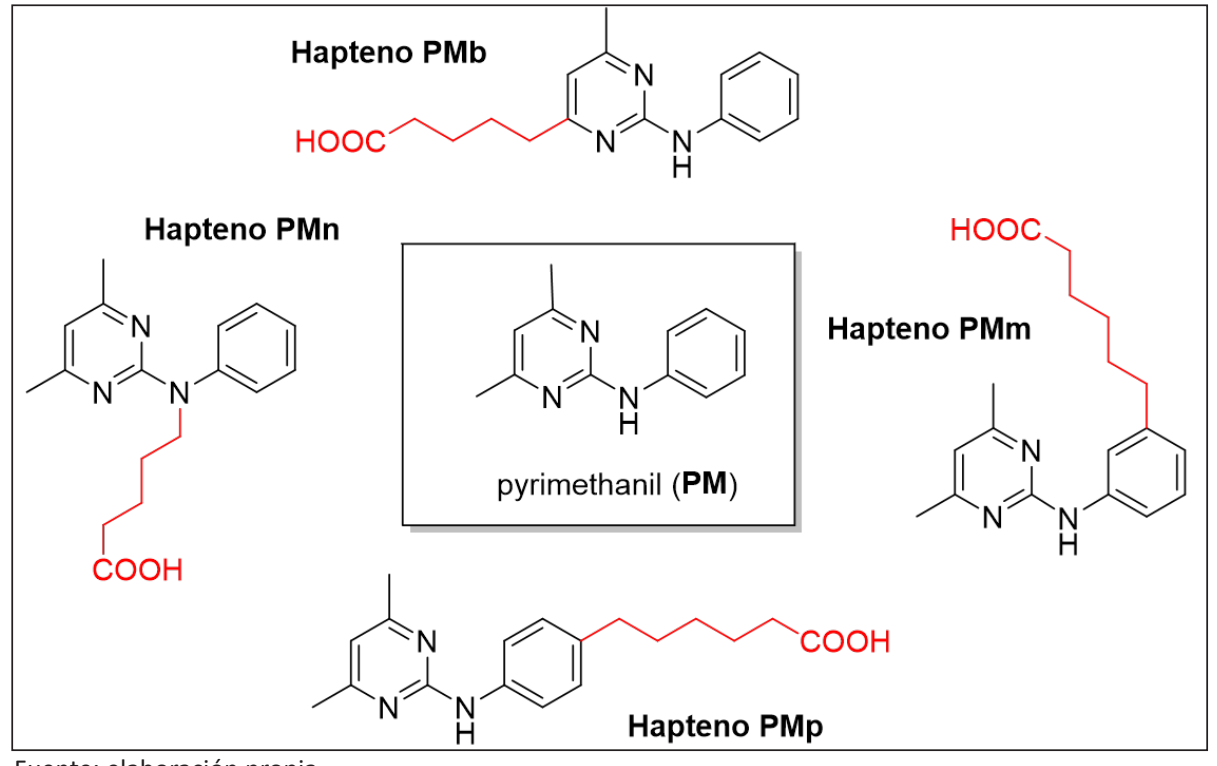

Fuente: elaboración propia 
bilidad, así como por su inmunogenicidad, estabilidad física y química, disponibilidad y bajo coste. Además, esta proteína es especialmente adecuada para cuantificar el número de moléculas de hapteno acopladas (densidad hapténica), y presenta una razonable tolerancia a disolventes orgánicos como el DMSO y la DMF, en los cuales normalmente son solubles los haptenos.

La naturaleza del grupo funcional del hapteno condiciona la química específica para realizar la conjugación. En el caso de haptenos con un grupo carboxilo terminal, probablemente el grupo funcional más utilizado, para que la reacción con los grupos amino libres de la proteína pueda realizarse en condiciones suaves que no afecten a su integridad estructural se precisa de una etapa previa de activación. Los procedimientos más empleados con esta finalidad son el método del éster activo y el del anhídrido mixto (Montalbetti y Falque, 2005). Una vez activado el grupo carboxilo, se hace reaccionar el hapteno con la proteína en medio ligeramente básico, de modo que los grupos amino de la proteína se encuentren parcialmente desprotonados y se facilite el acoplamiento con el grupo carbonilo de la especie química activada. Una característica muy reseñable del método del éster activo es la posibilidad de purificar el derivado de $N$-hidroxisuccinimidilo resultante de la activación, una aproximación en la que nuestro grupo ha sido pionero (Esteve-Turrillas et al., 2010). Si bien se trata de derivados bastante inestables, su manipulación en condiciones anhidras es perfectamente factible, y sin duda la utilización de derivados purificados y perfectamente caracterizados evita posibles reacciones secundarias indeseadas y facilita un control preciso de la proporción de moléculas de hapteno conjugadas por molécula de proteína, parámetro conocido como relación molar hapteno/proteína (RM). Los avances en técnicas de espectrometría de masas, como MALDI-TOF, permiten determinar con excelente exactitud pequeñas diferencias de masa en las proteínas, lo que posibilita calcular la densidad de haptenos por unidad proteica en los conjugados (véase figura 4) (Esteve-Turrillas, Mercader et al., 2015; Ramón-Azcón, Sánchez-Baeza, Sanvicens y Marco, 2009). Un conjugado inmunizante óptimo debe tener una carga hapténica moderadamente elevada. En el caso de la BSA, valores entre 10 y 20 moléculas de hapteno por molécula de proteína se consideran adecuados para la generación de una buena respuesta inmunitaria y por tanto para la producción de anticuerpos.

Figura 4. Espectros MALDI-TOF de la BSA y de diferentes conjugados con haptenos de ortofenilfenol

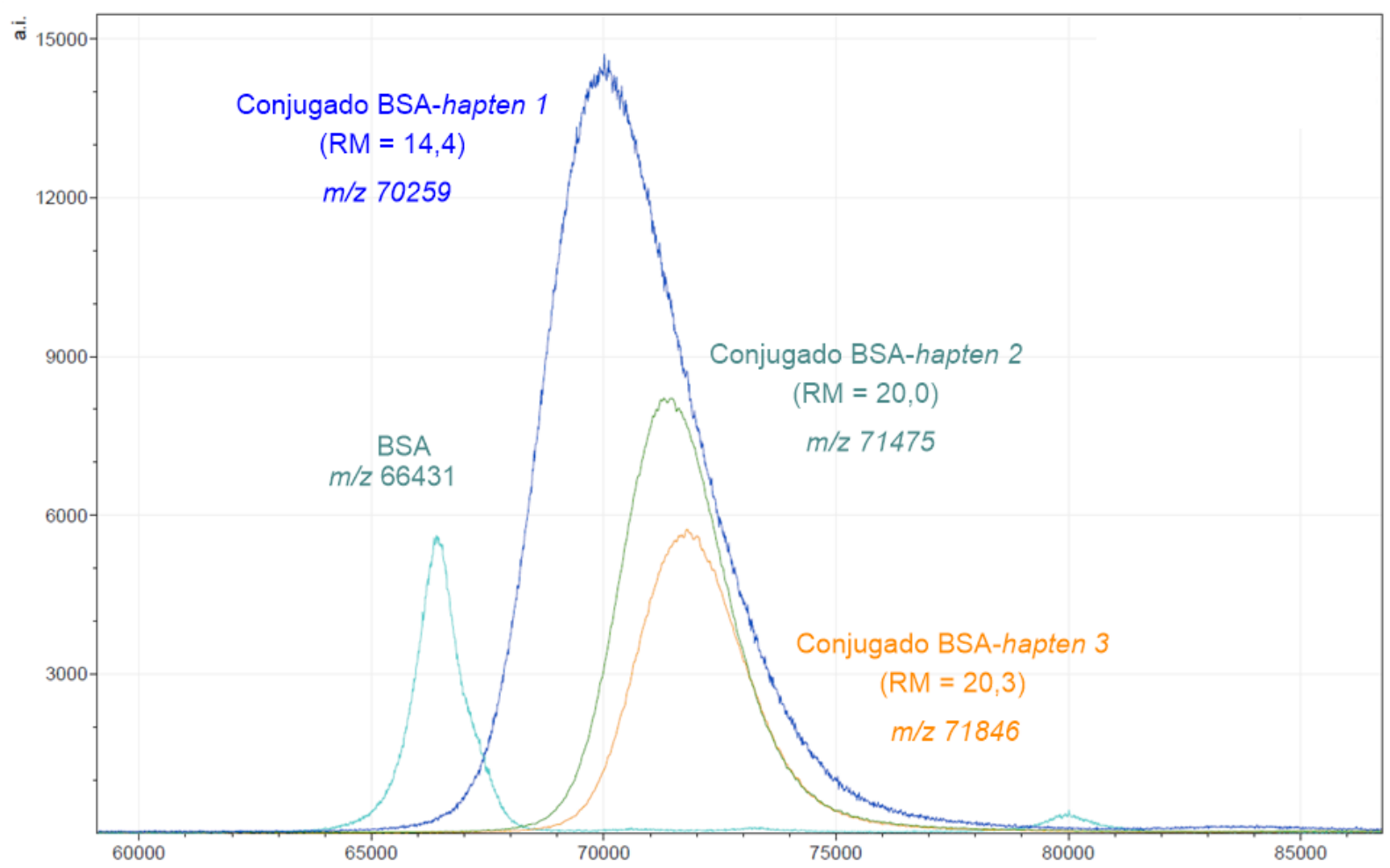

Fuente: elaboración propia 

MÉTODOS INMUNOQUÍMICOS HABITUALES EN EL
ANÁLISIS DE CONTAMINANTES DE ALIMENTOS

El tamaño de los haptenos no solo condiciona el procedimiento a seguir para obtener anticuerpos para este tipo de moléculas, también tiene una influencia capital en la configuración del inmunoensayo. El inmunoanálisis de proteínas y microorganismos se realiza habitualmente mediante lo que se conoce como inmunoensayo tipo sándwich, ya que debido a su gran tamaño estos antígenos poseen varios epítopos que les permiten unirse a varias moléculas de anticuerpo simultáneamente. Sin embargo, los compuestos de bajo peso molecular poseen un único epítopo, por lo que solo pueden interaccionar con una molécula de anticuerpo. Esta circunstancia determina que los inmunoensayos para haptenos sean de tipo competitivo (González-Techera, Varell, Last, Hammock y González-Sapienza, 2007).

En este tipo de inmunoensayo, el analito y una forma marcada del mismo compiten por los sitios de unión de una cantidad limitante de anticuerpo, de forma que cuanto más analito libre se encuentre en la muestra, más anticuerpo se unirá al mismo y menos al derivado marcado, por lo que se generará menos señal; por el contrario, en ausencia de analito se generará la máxima señal posible del ensayo. Por tanto, en un inmunoensayo de tipo competitivo, la señal obtenida será inversamente proporcional a la concentración de analito.

\section{Método ELISA}

Existen dos formatos básicos de ELISA competitivo, el formato de anticuerpo inmovilizado, también conocido como directo, y el formato de conjugado in- movilizado, conocido como indirecto. En el formato directo (figura 5), los pocillos de una microplaca de poliestireno se recubren con el anticuerpo específico. A continuación, se añade la muestra que contiene el analito y una concentración predeterminada del hapteno acoplado covalentemente a una enzima, al que se denomina trazador enzimático. En este momento tiene lugar una competición, ya que el anticuerpo puede unirse al analito o puede hacerlo al trazador. En función de la concentración de analito en la muestra y de la afinidad del anticuerpo, la fracción de anticuerpo unida a cada una de las dos especies será distinta. Después de una etapa de lavado se añade un sustrato, el cual será transformado por la enzima en un producto que generará una señal.

Como se puede ver en la figura 6, al representar la señal frente a la concentración de analito en escala logarítmica, se obtiene una curva sigmoide decreciente. Los parámetros más importantes de una curva de inhibición son los valores de señal máxima y mínima, la pendiente, y muy especialmente la concentración de analito en el punto de inflexión de la curva, denominada $\mathrm{IC}_{50}$, y que constituye una buena estimación de la constante de afinidad del anticuerpo. Obviamente, un inmunoensayo de este tipo será tanto más sensible cuanto menor sea el valor de $\mathrm{IC}_{50}$. Otros parámetros reseñables son la concentración de analito que origina una señal igual al $90 \%$ de la señal máxima $\left(I C_{10}\right)$, y que se suele adoptar como límite de detección del ensayo (LOD, de su acrónimo en inglés), y la que genera una señal igual al $80 \%$ de la señal máxima $\left(\mathrm{IC}_{20}\right)$, que se considera el límite de cuantificación (LOQ).

Figura 5. Esquema de un ELISA competitivo en formato directo

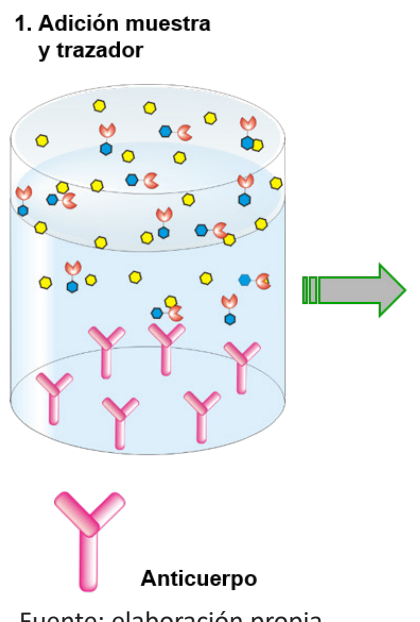

2. Lavado

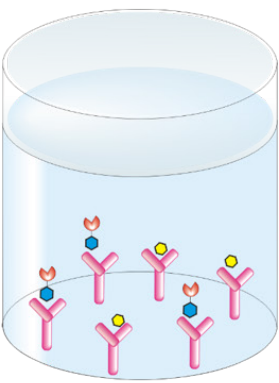

Trazador enzimático
3. Adición sustrato

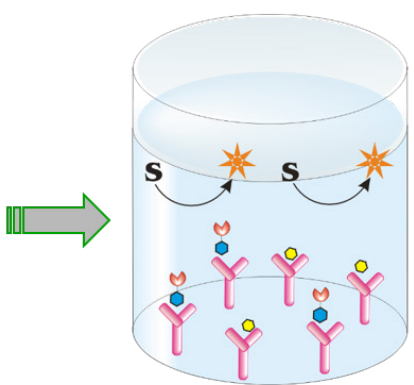

analito
4. Generación señal
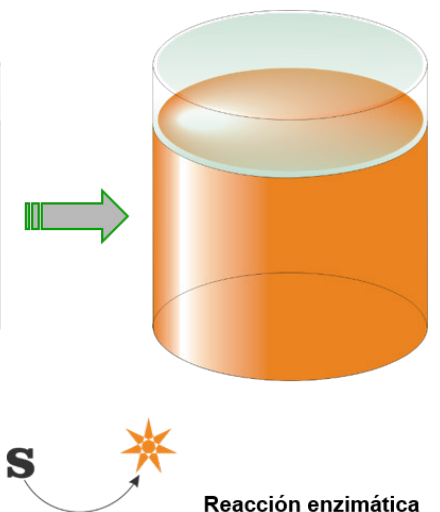

Reacción enzimática 
Figura 6. Curva de inhibición típica de un inmunoensayo competitivo

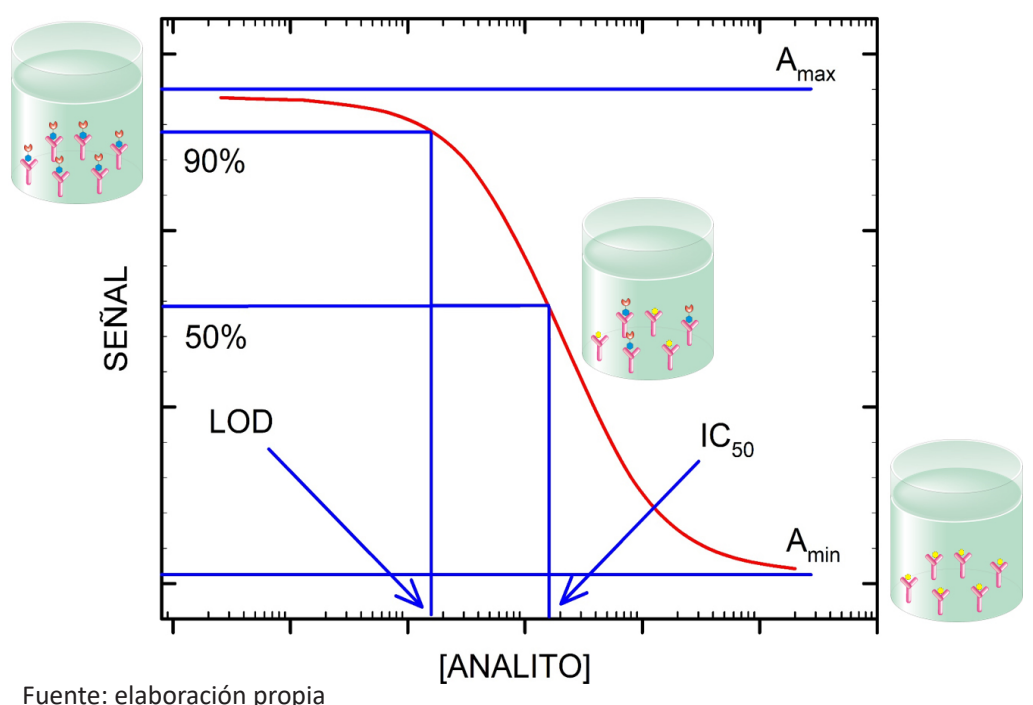

Probablemente, la enzima más empleada para la preparación del trazador sea la peroxidasa de rábano picante (HRP, horseradish peroxidase). En presencia de $\mathrm{H}_{2} \mathrm{O}_{2}$, la HRP promueve la oxidación de ciertos sustratos para dar lugar a productos con propiedades ópticas fácilmente detectables, siendo los más habituales el TMB (3,3',5,5'-tetrametilbencidina) y la OPD (o-fenilenodiamina) entre los cromogénicos, y el luminol (5-amino-2,3-dihidroftalazina-1,4-diona) entre los quimioluminiscentes.

En cuanto al formato indirecto (figura 7), es un conjugado no enzimático proteína-hapteno el que se inmoviliza en la microplaca. Al adicionar la muestra y una disolución con una concentración predeterminada del anticuerpo específico, se establece también una competición, ya que ahora el anticuerpo en disolución puede unirse al conjugado inmovilizado o puede hacerlo al analito si está presente en la muestra. Después de una etapa de lavado para eliminar el exceso de reactivos, se añade un anticuerpo marcado enzimáticamente que es capaz de reconocer al anticuerpo primario. La placa se lava de nuevo y se añade el sustrato, generándose la señal, que como corresponde a todo ELISA competitivo será también inversamente proporcional a la concentración de analito. El conjugado de ensayo que se emplea en este formato es esencialmente idéntico al que sirvió para generar el anticuerpo, si bien la proteína empleada suele ser diferente (habitualmente ovoalbúmina en lugar de BSA) y el grado de marcaje suele ser inferior para favorecer la competición y la sensibilidad del ensayo.

Figura 7. Esquema de un ELISA competitivo en formato indirecto

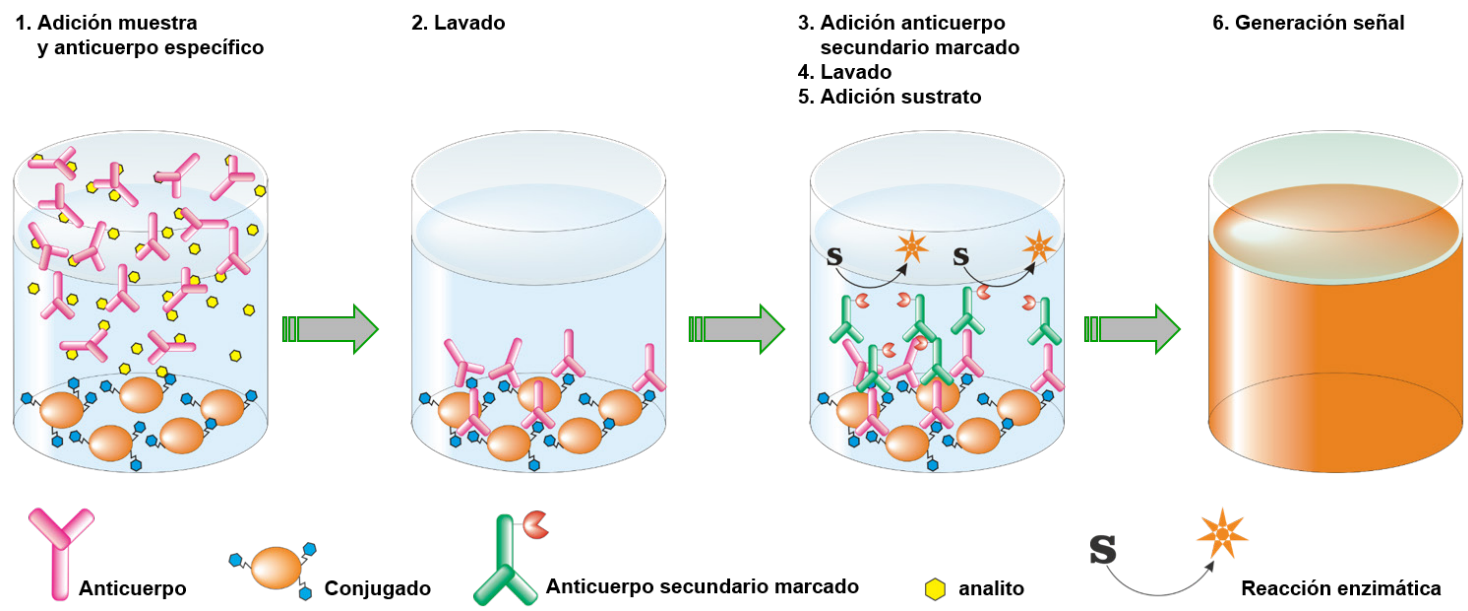

Fuente: elaboración propia 


\section{Inmunocromatografía de flujo lateral}

Otro método inmunoanalítico ampliamente empleado para la detección de xenobióticos y biotoxinas en alimentos es el inmunoensayo de flujo lateral o tiras inmunorreactivas, cuyo ejemplo más conocido proviene del campo de la química clínica, el test de embarazo. En este sistema (véase figura 8 ) se sustituye la microplaca de poliestireno típica de un ELISA por una membrana de nitrocelulosa sobre la que se ha depositado una fina línea de conjugado proteína-hapteno (línea test). Cuando la tira se pone en contacto con la muestra y con una cantidad previamente establecida de anticuerpo específico marcado, la disolución comienza a migrar por capilaridad hacia la zona donde se encuentra el conjugado. Existen muchas formas alternativas de marcar el anticuerpo, pero sin duda las nanopartículas de oro coloidal constituyen la solución más utilizada. Al llegar a la línea test, las moléculas de anticuerpo que no hayan interaccionado con el analito se unirán al conjugado inmovilizado en la membrana, generando una señal claramente visible en forma de banda roja. Por contra, las moléculas de anticuerpo que sí se hayan unido con el analito pasarán de largo.
Unos milímetros más arriba de la línea test se encuentra otra línea formada por inmunoglobulinas capaces de reconocer al anticuerpo marcado con independencia de que se encuentre libre o unido al analito (línea control), de forma que el anticuerpo específico que no haya quedado retenido en la línea test lo hará en dicha zona. Lógicamente, la cantidad de anticuerpo marcado que quede unido a cada línea, y por tanto la intensidad de señal de cada una de estas dos bandas, dependerá de la concentración de analito existente en la muestra que se está analizando, la cual se podrá estimar a partir de la relación de señales en las líneas test y control.

La gran ventaja de este sistema inmunoanalítico es que no requiere de ningún equipamiento especial para el análisis de muestras, por lo que el ensayo se puede realizar en cualquier entorno, con la ventaja analítica que esto supone. En el caso de que se requieran medidas cuantitativas, existen pequeños dispositivos realmente portátiles para leer las tiras, o incluso aplicaciones para teléfono móvil basadas en el tratamiento de la imagen capturada. Además, las tiras se pueden almacenar después del ensayo, garantizando la trazabilidad de los resultados.

Figura 8. Esquema simplificado de una tira inmunocromatográfica competitiva

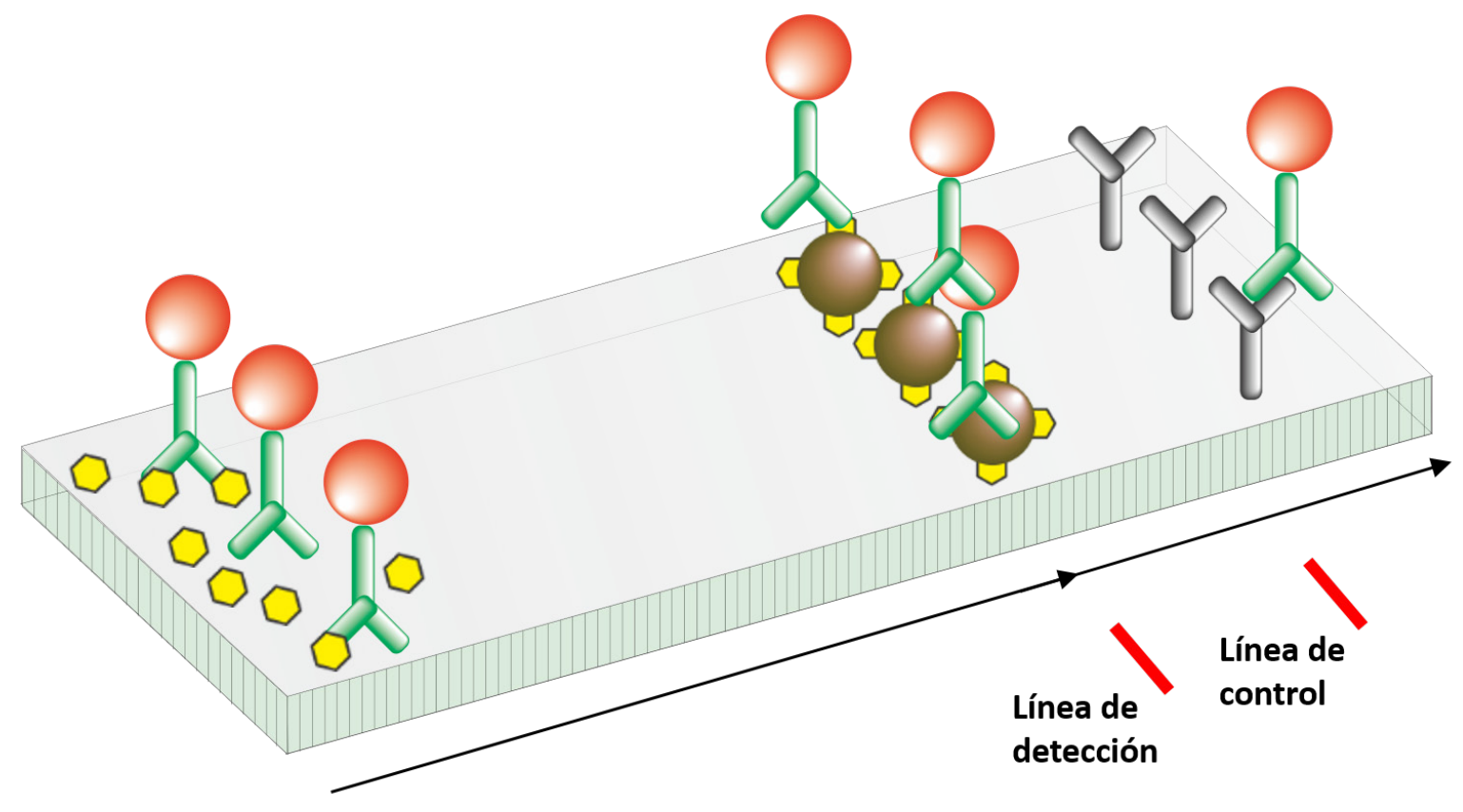

flujo

Anticuerpo marcado con oro

Analito
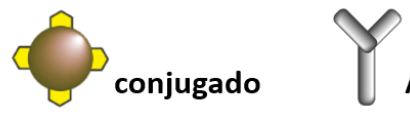

Anticuerpo de captura

Fuente: elaboración propia 


\section{DESARROLLO DE INMUNOENSAYOS Y SU VALIDA- CIÓN EN MUESTRAS DE ALIMENTOS}

La etapa previa al desarrollo de inmunoensayos consiste en la caracterización de los anticuerpos frente al conjugado homólogo (aquel que contiene el mismo hapteno que el del inmunógeno con el que se obtuvo el anticuerpo) y a posibles heterólogos. De este modo se estudia la afinidad del anticuerpo, así como su especificidad utilizando moléculas análogas al analito -comerciales o sintetizadas en el laboratorio- que permiten estudiar la interacción entre el anticuerpo y el ligando (López-Moreno, Mercader, Agulló, Abad-Somovilla y Abad-Fuentes, 2014; Suárez-Pantaleón, Mercader, Agulló, Abad-Somovilla y Abad-Fuentes, 2008).

A partir de los datos de caracterización se seleccionan las parejas anticuerpo-conjugado que proporcionan una señal adecuada en ausencia de analito y una mayor sensibilidad. El desarrollo de los inmunoensayos comienza con la optimización de la concentración de cada inmunorreactivo y de las condiciones de ensayo (tiempo, temperatura, volumen, etc.), y sigue con la determinación de los parámetros analíticos ( $A_{\text {max }^{\prime}} I C_{50}, L O D$, precisión, exactitud, etc.). A continuación, es necesario estudiar la selectividad del ensayo frente a moléculas que potencialmente pueden estar presentes en la muestra y que pueden ser reconocidas por el anticuerpo o interferir en el reconocimiento. Además, se debe determinar la influencia del pH y de la fuerza iónica del tampón de ensayo sobre los parámetros analíticos. Finalmente, también conviene evaluar la tolerancia a diferentes disolventes orgánicos, principalmente acetonitrilo, metanol y etanol, ya que son los que con mayor frecuencia se pueden encontrar en muestras de alimentos, bien porque se emplean para la extracción del analito, bien porque forman parte de ellas (AbadFuentes, Esteve-Turrillas, Agulló, Abad-Somovilla y Mercader, 2012; Esteve-Turrillas, Mercader, Agulló, Abad-Somovilla y Abad-Fuentes, 2015).

La etapa final en el desarrollo de todo método inmunoanalítico es la caracterización de sus prestaciones mediante el análisis de muestras reales. El procedimiento a seguir no difiere esencialmente del que se emplea con cualquier otro método de análisis, y consiste básicamente en establecer el protocolo más adecuado de extracción y limpieza de la muestra (en el caso de matrices sólidas); determinar las interferencias de la matriz alimentaria, si las hubiera; realizar estudios de recuperación con muestras fortificadas a diferentes niveles; y finalmente aplicar el ensayo a la determinación de alimentos contaminados de forma natural y validar los resultados obtenidos mediante comparación con otro método analítico (Mercader, López-Moreno, Esteve-Turrillas, Abad-Somovilla y Abad-Fuentes, 2014).

A lo largo de los últimos años, nuestro grupo de investigación ha producido anticuerpos, policlonales y monoclonales, y desarrollado inmunoensayos para un amplio abanico de compuestos relevantes en calidad y seguridad alimentaria, entre los que se incluyen:

- Cinco fungicidas de la familia de las estrobilurinas: azoxystrobin, pyraclostrobin, kresoxim-methyl, picoxystrobin y trifloxystrobin.

- Tres fungicidas de la familia de las anilinopirimidinas: pyrimethanil, cyprodinil y mepanipyrim.

- Cuatro inhibidores de la succinato deshidrogenasa fúngica: fluopyram, penthiopyrad, fluxapyroxad y boscalid.

- Siete fungicidas de diversas familias: ortofenilfenol, imazalil, fenhexamid, proquinazid, fludioxonil, quinoxyfen y fluopicolide.

- Dos insecticidas: spirotetramat e imidacloprid.

- Un herbicida: dicamba.

- Un antibiótico: cloranfenicol

- Dos hormonas: forchlorfenuron y melatonina.

- Seis micotoxinas: aflatoxina M1, aflatoxina B1, zearalenona, alternariol, ocratoxina $A$ y patulina.

- Una cianotoxina: anatoxina-a.

En las tablas 1, 2, 3 y 4 se recoge la información más relevante acerca de los inmunoensayos desarrollados por nuestro grupo que se han aplicado en diferentes matrices alimentarias, y se comparan sus LOQ con los límites máximos de residuos (MRL, de sus siglas en inglés) autorizados en la Unión Europea.

\section{APLICACIONES EN LA INDUSTRIA AGROALIMENTARIA}

Un gran número de empresas en todo el mundo centran su actividad en el inmunodiagnóstico de sustancias de interés para la industria agroalimentaria (Abraxis, Neogen, Envirologix, Zeulab, Tecna, Romer Labs, Unisensor, Prognosis Biotech, Randox, r-Biopharm, Vicam, Europroxima, Charm Sciences, Bioo Scientific, etc.), lo que da idea de la importancia económica de este sector. En este sentido, nuestro grupo ha participado en algunas iniciativas que han desembocado finalmente en métodos inmunoanalíticos disponibles comercialmente a través de diferentes empresas. 
Tabla 1. Ejemplos de inmunoensayos validados para el análisis de fungicidas estrobilurínicos en alimentos

\begin{tabular}{|c|c|c|c|c|c|}
\hline Analito & Anticuerpo & Formato & Muestra & $\begin{array}{c}\text { LOQ } \\
(\mu \mathrm{g} / \mathrm{L})\end{array}$ & $\begin{array}{c}M^{M R L^{a}} \\
(\mu \mathrm{g} / \mathrm{L})\end{array}$ \\
\hline \multirow[t]{5}{*}{ Azoxystrobin } & \multirow[t]{5}{*}{ mAb AZo\#49 } & ELISA indirecto & Zumo tomate & 3 & 3000 \\
\hline & & \multirow[t]{4}{*}{ heterólogo } & Zumo melocotón & 2 & 2000 \\
\hline & & & Zumo uva tinta & 2 & 2000 \\
\hline & & & Zumo banana & 5 & 2000 \\
\hline & & & Fresas & 4 & 50000 \\
\hline \multirow[t]{5}{*}{ Pyraclostrobin } & \multirow[t]{5}{*}{ mAb PYs\#11 } & \multirow{5}{*}{$\begin{array}{l}\text { ELISA directo } \\
\text { homólogo }\end{array}$} & Mermelada fresa & 50 & $100^{b}$ \\
\hline & & & Mermelada frambuesa & 50 & 3000 \\
\hline & & & Mermelada arándanos & 50 & 4000 \\
\hline & & & Mermelada albaricoque & 50 & 1000 \\
\hline & & & Mermelada melocotón & 50 & 300 \\
\hline \multirow[t]{7}{*}{ Picoxystrobin } & \multirow[t]{3}{*}{ mAb PCa\#21 } & ELISA indirecto & Harina trigo & 25 & 50 \\
\hline & & \multirow[t]{2}{*}{ heterólogo } & Harina avena & 50 & 300 \\
\hline & & & Harina centeno & 25 & 300 \\
\hline & \multirow[t]{4}{*}{ mAb PCa\#13 } & \multirow{4}{*}{$\begin{array}{l}\text { ELISA indirecto } \\
\text { homólogo }\end{array}$} & Cerveza Lager & 100 & 300 \\
\hline & & & Lager sin alcohol & 100 & 300 \\
\hline & & & Cerveza Ale negra & 100 & 300 \\
\hline & & & Cerveza Ale blanca & 100 & 300 \\
\hline \multirow{3}{*}{ Kresoxim-methyl } & \multirow[t]{3}{*}{ mAb KMo\#117 } & \multirow{3}{*}{$\begin{array}{l}\text { ELISA indirecto } \\
\text { homólogo }\end{array}$} & Tomates & 10 & 600 \\
\hline & & & Pepinos & 10 & $50^{\mathrm{b}}$ \\
\hline & & & Fresas & 10 & $50^{b}$ \\
\hline \multirow[t]{3}{*}{ Trifloxystrobin } & \multirow[t]{3}{*}{ mAb TF0\#17 } & \multirow{3}{*}{$\begin{array}{l}\text { ELISA indirecto } \\
\text { heterólogo }\end{array}$} & Tomates & 10 & 700 \\
\hline & & & Pepinos & 10 & 300 \\
\hline & & & Fresas & 10 & $50^{\mathrm{b}}$ \\
\hline
\end{tabular}

a Los valores son los últimos publicados por la UE para la correspondiente muestra original.

b Indica el límite inferior del método analítico.

Fuente: elaboración propia

Tabla 2. Ejemplos de inmunoensayos validados para el análisis de fungicidas anilinopirimidínicos en alimentos

\begin{tabular}{|c|c|c|c|c|c|}
\hline Analito & Anticuerpo & Formato & Muestra & $\begin{array}{c}\text { LOQ } \\
(\mu \mathrm{g} / \mathrm{L})\end{array}$ & $\begin{array}{l}\mathrm{MRL}^{\mathrm{a}} \\
(\mu \mathrm{g} / \mathrm{L})\end{array}$ \\
\hline \multirow[t]{4}{*}{ Pyrimethanil } & $\begin{array}{c}\text { pAb } \\
\text { PMp\#1 }\end{array}$ & $\begin{array}{l}\text { ELISA directo } \\
\text { homólogo }\end{array}$ & Zumo zanahoria & 40 & 1000 \\
\hline & \multirow{3}{*}{$\begin{array}{c}\mathrm{mAb} \\
\mathrm{PMm \# 31}\end{array}$} & \multirow{3}{*}{$\begin{array}{l}\text { ELISA indirecto } \\
\text { heterólogo }\end{array}$} & Fresas & 50 & $50^{b}$ \\
\hline & & & Tomates & 5 & 1000 \\
\hline & & & Pepinos & 5 & 700 \\
\hline \multirow[t]{7}{*}{ Cyprodinil } & \multirow{6}{*}{$\begin{array}{c}\mathrm{pAb} \\
\text { CDp\#2 }\end{array}$} & \multirow{6}{*}{$\begin{array}{l}\text { ELISA directo } \\
\text { homólogo }\end{array}$} & Zumo manzana & 20 & 1500 \\
\hline & & & Zumo uva tinta & 20 & 3000 \\
\hline & & & Vino blanco & 1 & 3000 \\
\hline & & & Vino tinto & 5 & 3000 \\
\hline & & & Vino espumoso & 1 & 3000 \\
\hline & & & Sidra & 1 & 1500 \\
\hline & $\begin{array}{c}m A b \\
C D m \# 21\end{array}$ & $\begin{array}{l}\text { ELISA directo } \\
\text { heterólogo }\end{array}$ & Fresas & 10 & $100^{b}$ \\
\hline
\end{tabular}

a Los valores son los últimos publicados por la UE para la correspondiente muestra original.

b Indica el límite inferior del método analítico.

Fuente: elaboración propia 
Tabla 3. Ejemplos de inmunoensayos validados para el análisis de fungicidas de diferentes familias en alimentos

\begin{tabular}{|c|c|c|c|c|c|}
\hline Analito & Anticuerpo & Formato & Muestra & $\begin{array}{c}\text { LOQ } \\
(\mu \mathrm{g} / \mathrm{L})\end{array}$ & $\begin{array}{l}M^{2} L^{a} \\
(\mu g / L)\end{array}$ \\
\hline \multirow[t]{6}{*}{ Boscalid } & \multirow{4}{*}{$\begin{array}{c}\text { pAb } \\
\text { BLa\#1 }\end{array}$} & \multirow{4}{*}{$\begin{array}{l}\text { ELISA directo } \\
\text { homólogo }\end{array}$} & Zumo uva tinta & 10 & 5000 \\
\hline & & & Zumo melocotón & 50 & 3000 \\
\hline & & & Zumo manzana & 10 & 2000 \\
\hline & & & Zumo tomate & 10 & 3000 \\
\hline & \multirow{2}{*}{$\begin{array}{c}\mathrm{pAb} \\
\mathrm{BLb \# 2}\end{array}$} & \multirow{4}{*}{$\begin{array}{c}\text { ELISA } \\
\text { indirecto } \\
\text { heterólogo } \\
\text { ELISA } \\
\text { indirecto } \\
\text { homólogo }\end{array}$} & Tomates & 5 & 3000 \\
\hline & & & Pepinos & 5 & 3000 \\
\hline \multirow[t]{2}{*}{ Fludioxonil } & \multirow{2}{*}{$\begin{array}{c}\text { mAb } \\
\text { FDn\#23 }\end{array}$} & & Zumo manzana & 5 & 5000 \\
\hline & & & Zumo uva tinta & 10 & 4000 \\
\hline \multirow[t]{6}{*}{ Fenhexamid } & \multirow{6}{*}{$\begin{array}{c}\text { mAb } \\
\text { FHo\#27 }\end{array}$} & \multirow{6}{*}{$\begin{array}{l}\text { ELISA directo } \\
\text { homólogo }\end{array}$} & Zumo uva tinta & 75 & 15000 \\
\hline & & & Zumo uva blanca & 30 & 15000 \\
\hline & & & Vino tinto & 75 & 15000 \\
\hline & & & Vino blanco & 75 & 15000 \\
\hline & & & Kiwis verdes & 10 & 15000 \\
\hline & & & Fresas & 25 & $50^{b}$ \\
\hline \multirow[t]{3}{*}{ Fluopyram } & \multirow{3}{*}{$\begin{array}{c}\mathrm{mAb} \\
\mathrm{FPb \# 12}\end{array}$} & \multirow{3}{*}{$\begin{array}{l}\text { ELISA directo } \\
\text { homólogo }\end{array}$} & Uvas & 5 & 1500 \\
\hline & & & Vinos & 10 & 1500 \\
\hline & & & Ciruelas & 5 & 500 \\
\hline
\end{tabular}

a Los valores son los últimos publicados por la UE para la correspondiente muestra original.

${ }^{\mathrm{b}}$ Indica el límite inferior del método analítico.

Fuente: elaboración propia

Tabla 4. Ejemplos de inmunoensayos validados para el análisis de diversas biotoxinas en alimentos

\begin{tabular}{|c|c|c|c|c|c|}
\hline Analito & Anticuerpo & Formato & Muestra & $\begin{array}{c}\mathrm{LOQ} \\
(\mu \mathrm{g} / \mathrm{L})\end{array}$ & $\begin{array}{l}\mathrm{MRL}^{\mathrm{a}} \\
(\mu \mathrm{g} / \mathrm{L})\end{array}$ \\
\hline \multirow{2}{*}{ Ocratoxina A } & \multirow{2}{*}{ mAb OTAf\#223 } & \multirow{2}{*}{$\begin{array}{l}\text { ELISA directo } \\
\text { heterólogo }\end{array}$} & Vino blanco & 0.5 & 2 \\
\hline & & & Vino tinto & 0.5 & 2 \\
\hline Aflatoxina M1 & mAb AFM1\#314 & $\begin{array}{l}\text { ELISA indirecto } \\
\text { heterólogo }\end{array}$ & Tampón & $0.04^{b}$ & $0.05^{c}$ \\
\hline Anatoxina-a & $\mathrm{mAb}$ ANm\#38 & $\begin{array}{l}\text { ELISA captura } \\
\text { heterólogo }\end{array}$ & $\begin{array}{c}\text { Aguas } \\
\text { medioambientales }\end{array}$ & 0.25 & $0.1-20^{d}$ \\
\hline
\end{tabular}

a Los valores son los últimos publicados por la UE para la correspondiente muestra original.

${ }^{b}$ Valor de $\mathrm{IC}_{50}$ en tampón.

c Límite máximo tolerable.

d El valor máximo regulado depende del país.

Fuente: elaboración propia

\section{Determinación de fungicidas en postcosecha de frutas}

Dada su propensión a resultar infectadas por patógenos fúngicos, las frutas son enviadas inmediatamente después de su recolección a centrales hortofrutícolas, donde son tratadas con fungicidas para evitar su deterioro. Dichos tratamientos deben realizarse de acuerdo con la legislación vigente para no exceder los límites máximos de residuos, al tiempo que deben resultar eficaces. Así, si se aplican concen- traciones inferiores a las recomendadas, se producirá un aumento del podrido en destino que puede llevar a importantes pérdidas económicas. Si por el contrario se trata la fruta con un exceso de fungicida, el residuo en el fruto se incrementará, pudiéndose superar los límites legales.

La forma habitual por la que un almacén controla que las concentraciones en los caldos de tratamiento y en la fruta final son las adecuadas es el envío de 
muestras a laboratorios acreditados. Estos análisis se llevan a cabo mediante técnicas cromatográficas, y pueden tardar días o incluso semanas en el caso de países con escasas infraestructuras analíticas. En definitiva, las centrales hortofrutícolas carecen de herramientas rápidas que les permitan realizar un control efectivo sobre un proceso crítico, como es el de los tratamientos que realizan.

Ante esta situación, y en colaboración con la empresa Productos Citrosol, decidimos desarrollar un sistema inmunoanalítico que permitiera determinar en las propias centrales hortofrutícolas los tres fungicidas más utilizados en postcosecha de cítricos, es decir, imazalil, ortofenilfenol y pyrimethanil. Las características clave del sistema son su rapidez (los resultados se obtienen en treinta minutos), su sencillez (no se requiere una formación especializada), su coste (menos de $10 €$ por muestra) y sobre todo su portabilidad (los análisis se realizan en el propio almacén, dado que no se requiere un equipamiento sofisticado). El sistema, basado en kits ELISA, proporciona resultados comparables a los obtenidos en laboratorios acreditados, permitiendo mejorar de forma considerable los sistemas de calidad en los almacenes de tratamiento. El sistema supone una importante innovación para el sector de la postcosecha, en tanto que permite adoptar medidas correctoras en tiempo real, evitando así situaciones inesperadas e indeseables. Desde principios de 2018, Productos Citrosol comercializa estos ensayos en exclusiva a nivel mundial bajo la denominación Easy Kit, con un nivel de aceptación por parte del sector que está superando las previsiones iniciales de la empresa.

\section{Análisis de cloranfenicol y aflatoxina M1 en leche}

Uno de los campos donde los métodos inmunoanalíticos gozan de un mayor grado de implantación es en la determinación de antibióticos y micotoxinas en alimentos. Los antibióticos son sustancias ampliamente utilizadas en la práctica veterinaria para el tratamiento de enfermedades y de infecciones microbianas. El uso excesivo de antibióticos puede acarrear la presencia de sus residuos en leche, lo que supone no solo un problema de salud pública por la aparición de reacciones alérgicas y de bacterias resistentes, sino también industrial por los problemas que genera a la industria de derivados lácteos. El cloranfenicol es un antibiótico de amplio espectro prohibido en la Unión Europea, Estados Unidos y otros países para usos veterinarios en animales destinados al consumo humano. Sin embargo, debido a su elevada eficacia y bajo coste, este fármaco se sigue utilizando de for- ma fraudulenta, especialmente en países con legislaciones más laxas y con sistemas de seguridad alimentaria menos rigurosos, y con frecuencia muchos productos alimenticios con residuos de cloranfenicol tienen a Europa como destino final.

En colaboración con la empresa de inmunodiagnóstico Zeulab, hemos generado anticuerpos monoclonales con una extraordinaria afinidad hacia cloranfenicol. Estos anticuerpos, y los conjugados preparados para su obtención, han permitido el desarrollo de un test rápido inmunocromatográfico que posibilita la detección de la presencia de cloranfenicol en leches y derivados en menos de diez minutos y a niveles por debajo de $0.3 \mu \mathrm{g} / \mathrm{L}$, el nivel permitido más exigente de las legislaciones en vigor, y que corresponde a la Unión Europea. Este test se encuentra en este momento en fase de producción a gran escala con vistas a su inmediata comercialización. En esta misma línea de colaboración, cabe señalar que actualmente se encuentra en fase de desarrollo un sistema, también de tipo inmunocromatográfico, que permita la detección de aflatoxina $\mathrm{M} 1$ en leche a un nivel tan analíticamente exigente como $0.05 \mu \mathrm{g} / \mathrm{L}$, acorde con la reglamentación promulgada por la Unión Europea para esta micotoxina en productos lácteos.

\section{Detección de anatoxina-a en aguas}

Las cianobacterias son organismos fotosintéticos procariotas que bajo condiciones favorables son capaces de proliferar muy rápidamente. Se considera que estas proliferaciones masivas son más frecuentes e intensas que antaño debido a la actividad humana y al calentamiento global. Algunas de estas cianobacterias son capaces de producir metabolitos tóxicos conocidos como cianotoxinas, los cuales suponen una seria amenaza para los ecosistemas y la salud humana, así como para el bienestar de la fauna, el ganado y los animales domésticos. Las principales vías de exposición a cianotoxinas son la ingesta de agua contamina$\mathrm{da}$, el consumo de pescado y moluscos, y la presencia de especies cianobacterianas indeseadas en suplementos dietéticos.

La anatoxina-a es una cianotoxina identificada en los años '60 como el agente causante de la muerte de ganado vacuno en Canadá. Se trata de una neurotoxina muy potente que se une de manera irreversible al receptor de acetilcolina, provocando la muerte por parálisis debido a la sobreexcitación del impulso nervioso. En algunas regiones el problema es recurrente y se registran incidentes cada año, como la clausura del suministro de agua potable 
para consumo humano, o la muerte de fauna salvaje y animales domésticos por el consumo accidental de aguas contaminadas. La anatoxina-a es una molécula muy pequeña y poco compleja estructuralmente, por lo que a pesar de los esfuerzos realizados durante los últimos treinta años, no había sido posible producir anticuerpos frente a ella y en consecuencia desarrollar métodos inmunoanalíticos que permitieran su detección de forma rápida y sencilla. En 2015, nuestro grupo fue capaz de lograr la generación de anticuerpos monoclonales capaces de reconocer anatoxina-a con una elevada afinidad y enantioselectividad. Este desarrollo dio lugar a la presentación de una patente internacional que se licenció en exclusiva a la empresa estadounidense Abraxis Inc (https://digital.csic.es/bitstream/10261/176373/1/ ES2612751R1.pdf), quien actualmente comercializa los únicos inmunoensayos tipo ELISA y tiras inmunocromatográficas disponibles a nivel mundial para la detección de esta cianotoxina. Además, esta empresa comercializa kits tipo ELISA para el insecticida imidacloprid y para los fungicidas azoxystrobin y pyraclostrobin, basados en inmunorreactivos desarrollados por nuestro grupo.

\section{Determinación de ocratoxina $A$ en vinos}

La ocratoxina A es un metabolito secundario tóxico producido principalmente por hongos del género Aspergillus que pueden contaminar productos agrícolas y alimentos procesados a lo largo de toda la cadena alimentaria. La International Agency for Research on Cancer clasifica la ocratoxina A dentro del grupo 2B de sustancias potencialmente carcinogénicas en humanos. Esta micotoxina se encuentra en diferentes alimentos contaminados por hongos toxigénicos, principalmente cereales, pero también en bebidas como el café, la cerveza y el vino. De hecho, la ocratoxina $A$ es la única micotoxina para la cual la Autoridad Europea de Seguridad Alimentaria (EFSA) ha establecido niveles máximos permitidos en vinos y mostos, en concreto $2 \mu \mathrm{g} / \mathrm{L}$. Los datos disponibles sugieren la necesidad de vigilar la presencia de ocratoxina $A$ en vino, y no solo por una cuestión evidente de seguridad alimentaria, sino también de calidad, ya que su presencia en esta matriz constituye un indicador de una deficiente selección de la materia prima. Recientemente nuestro grupo ha generado los que probablemente sean los anticuerpos monoclonales de mayor afinidad hacia esta micotoxina producidos hasta la fecha. Esto ha sido posible gracias a la utilización de estrategias sintéticas innovadoras no exploradas con anterioridad que han permitido preparar derivados funcionalizados de la micotoxina, dejando libre, y por tanto accesible, el grupo carboxilo que la ocratoxina A posee en su estructura. Con estos inmunorreactivos hemos desarrollado un inmunoensayo capaz de determinar con fiabilidad la presencia de ocratoxina A en vinos a una concentración de $0.5 \mu \mathrm{g} / \mathrm{L}$, un nivel cuatro veces inferior al establecido en la legislación europea. A modo de ejemplo, el análisis de un material certificado (ERM-BD476) proporcionado por el Federal Institute for Materials Research and Testing de Alemania, y consistente en un vino tinto contaminado de forma natural con $0.5 \mu \mathrm{g} / \mathrm{L}$ de ochatoxina $\mathrm{A}$, proporcionó un valor mediante ELISA de $0.45 \pm 0.07$ $\mu \mathrm{g} / \mathrm{L}(\mathrm{n}=7)$. Estos desarrollos han sido debidamente patentados, y en la actualidad estamos negociando con empresas de inmunodiagnóstico alimentario interesadas en su licencia y comercialización. Consideramos que, al igual que ha ocurrido con el sector de la postcosecha mencionado anteriormente, el acceso a una herramienta analítica de este tipo por parte de las bodegas les permitiría controlar in situ y de una forma sencilla, rápida y económica, la calidad de sus vinos y de las materias primas, uvas y mostos con los que se elaboran.

\section{AGRADECIMIENTOS}

Estos estudios fueron financiados con proyectos de diferentes convocatorias públicas (GVPRE/2008/236, AICO/2018/111, AGL2006-12750-C02-01/ALI, AGL200912940-C02-01-02/ALI, AGL2012-39965-C02, AGL201564488-C2, PET2006-0423-00, IDI-20140850, RTC-20153348-2) y cofinanciados con fondos FEDER. Nos gustaría expresar nuestro reconocimiento a todos los estudiantes y técnicos que han formado parte de nuestro grupo por su decisiva contribución en la generación de la colección de inmunorreactivos que se describe en este artículo. 


\section{BIBLIOGRAFÍA}

Abad-Fuentes, A., Esteve-Turrillas, F. A., Agulló, C., Abad-Somovilla, A. y Mercader, J. V. (2012). Development of competitive enzyme-linked immunosorbent assays for boscalid determination in fruit juices. Food Chemistry, 135 (1) pp. 276-284. https://doi.org/10.1016/j. foodchem.2012.04.090

Esteve-Turrillas, F. A., Abad-Somovilla, A. Quiñones-Reyes, G., Agulló, C., Mercader, J. V. y Abad-Fuentes, A. (2015). Monoclonal antibody-based immunoassays for cyprodinil residue analysis in QuEChERS-based fruit extracts. Food Chemistry, 187, pp. 530-536. https://doi. org/10.1016/j.foodchem.2015.04.119

Esteve-Turrillas, F. A., Mercader, J. V., AguIló, C., Abad-Somovilla, A. y Abad-Fuentes, A. (2015). Moiety and linker site heterologies for highly sensitive immunoanalysis of cyprodinil in fermented alcoholic drinks. Food Control, 50, pp. 393-400. https://doi.org/10.1016/j.foodcont.2014.09.023

Esteve-Turrillas, F. A., Parra, J., Abad-Fuentes, A., Agulló, C., Abad-Somovilla, A. y Mercader, J. V. (2010). Hapten synthesis, monoclonal antibody generation, and development of competitive immunoassays for the analysis of picoxystrobin in beer. Analytica Chimica Acta, 682 (1-2), pp. 93-103. https://doi. org/10.1016/j.aca.2010.09.042

González-Techera, A., Varell, L., Last, J. A., Hammock, B. D. y González-Sapienza, G. (2007). Phage anti-immune complex assay: General strategy for non-competitive immunodetection of small molecules. Analytical Chemistry, 79 (20), pp. 7799-7806. https://doi.org/10.1021/ ac071323h

Landsteiner, K. y Simms, S. (1923). Production of heterogenetic antibodies with mixtures of the binding part of the antigen and protein. Journal of Experimental Medicine, 38 (2), pp. 127-138. https://doi.org/10.1084/jem.38.2.127

López-Moreno, R., Mercader, J. V., Agulló, C., Abad-Somovilla, A. y Abad-Fuentes, A. (2014). Immunoassays for trifloxystrobin analysis. Part I. Rational design of regioisomeric haptens and production of monoclonal antibodies. Food Chemistry, 152, pp. 230-236. https://doi. org/10.1016/j.foodchem.2013.11.150

López-Puertollano, D., Mercader, J. V., AguIló, C., Abad-Somovilla, A. y Abad-Fuentes, A. (2018). Novel hapten and monoclonal antibodies with subnanomolar affinity for a classical analytical target, ochratoxin A. Scientific Reports, 8 (1), 9761. https://doi.org/10.1038/s41598018-28138-x

Mercader, J. V., Agulló, C., Abad-Somovilla, A. y Abad-Fuentes, A. (2011). Synthesis of site-heterologous haptens for highaffinity anti-pyraclostrobin antibody generation. Organic \& Biomolecular Chemistry, 9 (5), pp. 1443-1453. https:// doi.org/10.1039/c0ob00686f

Mercader, J. V., López-Moreno, R., EsteveTurrillas, F. A., Abad-Somovilla, A. y Abad-Fuentes, A. (2014). Immunoassays for trifloxystrobin analysis. Part II. Assay development and application to residue determination in food. Food Chemistry, 162, pp. 41-46. https://doi. org/10.1016/j.foodchem.2014.04.053

Montalbetti, C. A. G. N. y Falque, V. (2005). Amide bond formation and peptide coupling. Tetrahedron, 61 (46), pp. 1082710852 . https://doi.org/10.1016/j. tet.2005.08.031

Parra, J., Mercader, J. V., Agulló, C., AbadSomovilla, A. y Abad-Fuentes, A. (2012). Generation of anti-azoxystrobin monoclonal antibodies from regioisomeric haptens functionalized at selected sites and development of indirect competitive immunoassays. Analytica Chimica Acta, 715, pp. 105-112. https://doi. org/10.1016/j.aca.2011.12.014

Ramón-Azcón, J., Sánchez-Baeza, F., Sanvicens, N. y Marco, M. P. (2009). Development of an enzyme-linked immunosorbent assay for determination of the miticide bromopropylate. Journal of Agricultural and Food Chemistry, 57 (2), pp. 375-384. https://doi.org/10.1021/ jf802821n

Sanvicens, N., Pichon, V., Hennion, M. C. y Marco, M. P. (2003). Preparation of antibodies and development of an enzymelinked immunosorbent assay for determination of dealkylated hydroxytriazines. Journal of Agricultural and Food Chemistry, 51 (1), pp. 156-164. https:// doi.org/10.1021/jf025640v

Suárez-Pantaleón, C., Mercader, J. V., AguIló, C., Abad-Somovilla, A. y Abad-Fuentes, A. (2008). Production and characterization of monoclonal and polyclonal antibodies to forchlorfenuron. Journal of Agricultural and Food Chemistry, 56 (23), pp. 11122-11131. https://doi. org/10.1021/jf802261x

Suárez-Pantaleón, C., Mercader, J. V., Agulló, C., Abad-Somovilla, A. y AbadFuentes, A. (2011). Forchlorfenuron-mimicking haptens: from immunogen design to characterization by hierarchical clustering analysis. Organic \& Biomolecular Chemistry, 9 (13), pp. 4863-4872. https://doi.org/10.1039/c1ob05190c

Vallejo, R. P., Bogus, E. R. y Mumma, R. O. (1982). Effects of hapten structure and bridging groups on antisera specificity in parathion immunoassay development. Journal of Agricultural and Food Chemistry, 30 (3), pp. 572-580. https:// doi.org/10.1021/jf00111a040 